OPEN ACCESS

Edited by: Jessica Dal Col,

University of Salerno, Italy

Reviewed by:

Joshua Brody,

Icahn School of Medicine at Mount

Sinai, United States

María Marcela Barrio,

Fundación Cáncer, Argentina

${ }^{*}$ Correspondence:

Luciano Castiello

luciano.castiello@iss.it

Specialty section:

This article was submitted to

Cancer Immunity and Immunotherapy,

a section of the journal

Frontiers in Immunology

Received: 04 July 2019 Accepted: 11 September 2019

Published: 25 September 2019

Citation:

Castiello L, Aricò E, D'Agostino G, Santodonato $L$ and Belardelli $F$ (2019) In situ Vaccination by Direct Dendritic Cell Inoculation: The Coming of Age of an Old ldea?

Front. Immunol. 10:2303. doi: 10.3389/fimmu.2019.02303

\section{In situ Vaccination by Direct Dendritic Cell Inoculation: The Coming of Age of an Old Idea?}

\author{
Luciano Castiello $^{1 *}$, Eleonora Aricò ${ }^{1}$, Giuseppina D'Agostino ${ }^{1}$, Laura Santodonato ${ }^{1}$ and \\ Filippo Belardelli ${ }^{2}$
}

${ }^{1}$ FaBioCell, Core Facilities, Istituto Superiore di Sanità, Rome, Italy, ${ }^{2}$ Consiglio Nazionale Delle Ricerche, Institute of Translational Pharmacology, Rome, Italy

For more than 25 years, dendritic cell (DC) based vaccination has flashily held promises to represent a therapeutic approach for cancer treatment. While the vast majority of studies has focused on the use of antigen loaded DC, the intratumoral delivery of unloaded DC aiming at in situ vaccination has gained much less attention. Such approach grounds on the ability of inoculated DC to internalize and process antigens directly released by tumor (usually in combination with cell-death-inducing agents) to activate broad patient-specific antitumor T cell response. In this review, we highlight the recent studies in both solid and hematological tumors showing promising clinical results and discuss the main pitfalls and advantages of this approach for endogenous cancer vaccination. Lastly, we discuss how in situ vaccination by DC inoculation may fit with current immunotherapy approaches to expand and prolong patient response.

Keywords: dendritic cell (DC), in situ vaccination, cancer immunotherapy, checkpoint inhibitor combination therapy, intratumor administration, monocyte derived dendritic cells (MoDC)

\section{INTRODUCTION}

Since the discovery that monocytes, cultured with GM-CSF and IL-4, differentiate into dendritic cells (DC) (1), the idea to use ex vivo generated DC to vaccinate cancer patients against tumor antigens has been largely explored $(2,3)$. Many different protocols have been developed for DC differentiation and/or maturation (4), but there is still a strong need to characterize the relationship between ex vivo derived DC and the several in vivo circulating DC subsets for which many information are now available in terms of phenotype and functionality (5). Over the last 25 years, hundreds of clinical trials have been performed mostly without showing consistent clinical responses, despite some encouraging results, especially in recent years (6-8). The vast majority of these studies have used mature IL-4-conditioned-DC loaded ex vivo with tumor antigens. However, antigen selection has represented one of the major limitations of DC vaccines and it is now widely accepted that broad patient-specific antigen repertoire, using patient tumor lysate or mutanome-derived peptides, represents the most promising DC antigen source (7-10).

An alternative to ex vivo antigen loading is represented by the so-called in situ vaccination. In situ vaccination aims at stimulating DC in the tumor to capture and process antigens released by the tumor and present them to immune cells upon migration to draining lymph node. This approach is receiving renewed interest because of the necessity to expand the antigenic repertoire of $\mathrm{T}$ cell responses in the checkpoint blockade therapy era (11-16). Several approaches are being evaluated in early trials, mostly using DC activators directly inoculated within the tumor $(13,16)$. However, given the low number of pre-existing DC at tumor site, combination therapy with 
stimulator of hematopoietic differentiation of DC, such as Flt3L, seems to be required for efficient DC activation (17-19).

One way to overcome low intratumoral DC number and ensure a better control of DC phenotype is represented by intratumoral inoculation of ex vivo generated DC (itDC) aimed at an in situ vaccination. First attempts of itDC date 20 years back (20-22). Since the initial studies, many promising observations were collected on feasibility and efficacy of itDC (23-28), even though they did not get under the spot into the mainstream DC vaccine field. However, recent clinical results (29-31), together with increased interest in in situ vaccination to enforce current immunotherapies, highlight itDC as a powerful approach that can be rapidly implemented in current checkpoint blockade therapies. In this review, we will present the main results collected in pre-clinical and clinical use of intratumoral delivery of DC and discuss their potential use in combination with current immunotherapy.

\section{INTRATUMOR INJECTION OF DC: A PLATFORM FOR ENDOGENOUS VACCINATION}

As professional antigen processing cells, DCs are characterized by the ability to internalize, process and present antigens and potently interact with $\mathrm{T}$ cells, thus inducing their activation (32). However, tumors develop several "escape mechanisms" to exclude or reduce immune recognition of tumor-associated antigens, including DC exclusion from tumor microenvironment (33) and inhibition of DC activity (34). Within such an immunosuppressive environment, the injection of ex vivo cultured DC represents a valuable approach to overcome some tumor escape mechanisms, process antigens released in necrotic or apoptotic tumor mileu and activate immune response against tumor-associated antigens (35). itDC can be potentially applied to almost any tumor type: the only pre-requisite is the possibility

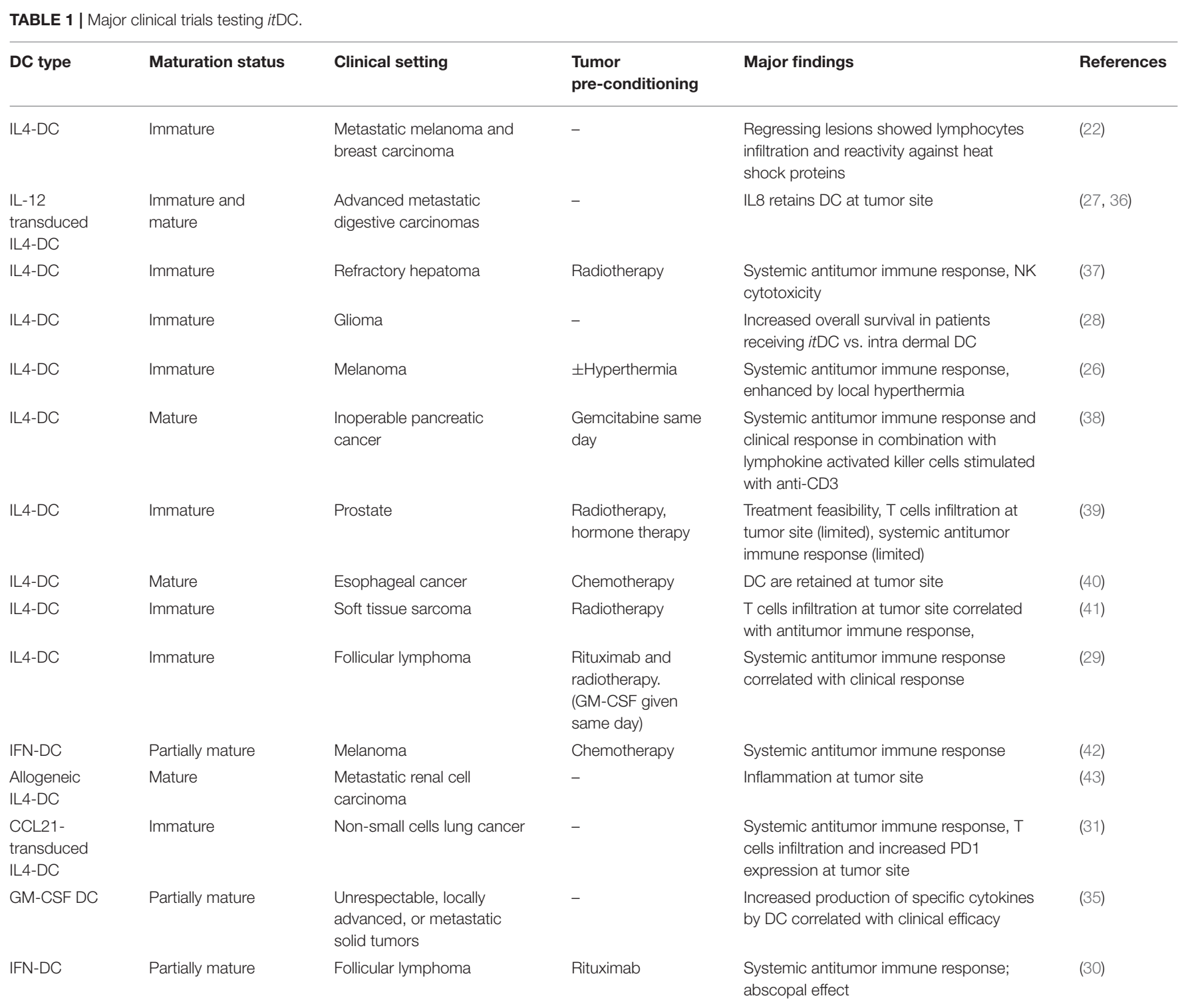


A

Without
preconditioning

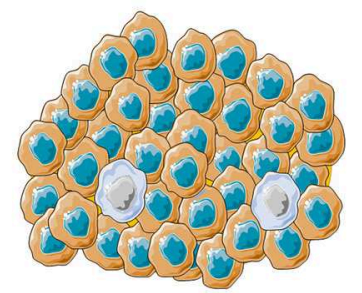

With

preconditioning

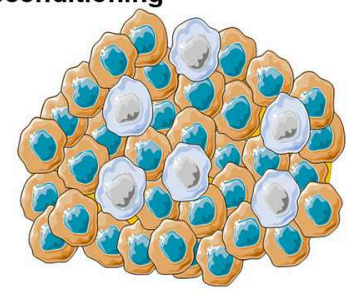

Low tumor cell death

Low antigen release

Immunosuppresive TME

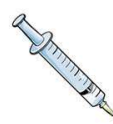

immunotherapy

High tumor cell death

Increased antigen release

Immune activating TME intratumor DC
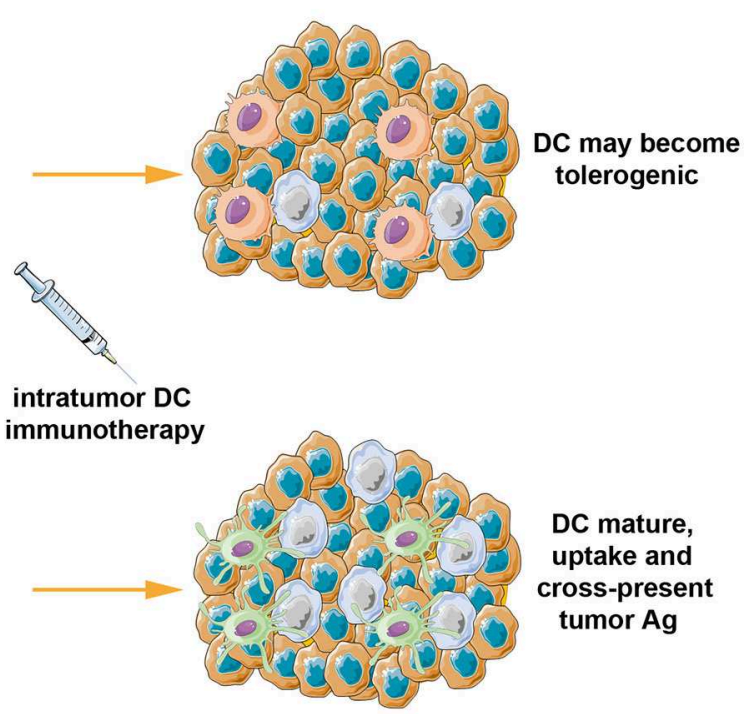

DC mature, uptake and cross-present tumor Ag

B

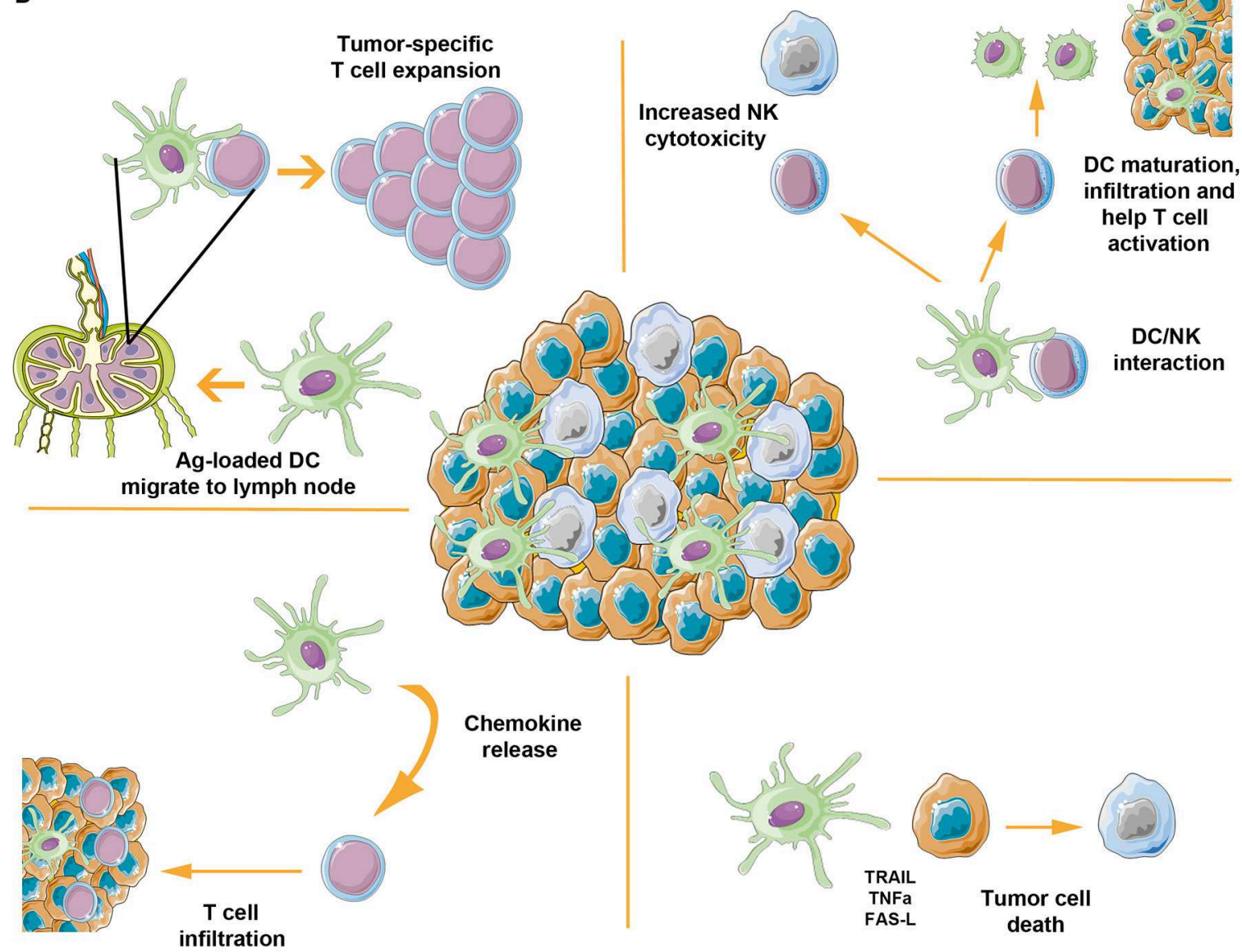

FIGURE 1 | Intratumor inoculation of DC: the importance of preparing tumor microenvironment and its multiple ways of action. (A) In the absence of any treatment, tumors are characterized by low levels of basal apoptotic/necrotic cells and an immunosuppressive microenvironment. Within this setting, itDC might become 
FIGURE 1 | tolerogenic, thus increasing tumor immunosuppressive features and eventually causing a detrimental effect. Tumor preconditioning with immunogenic cell death agents, instead, can enhance tumor cells apoptosis, resulting in increased release of tumor-associated antigens and immune activating signals. In this scenario, intratumor inoculated DC sense proinflammatory and immune activating signals, process tumor antigens, and activate antitumor response. (B) itDC can activate immune response by acting on several mechanisms. After loading tumor released antigens, mature DC migrate to draining lymph node where they interact with $T$ cells and lead to increased clonality and richness of antitumor T cell responses. The DC interaction with intratumor NK cells can activate their cytotoxic activity, which in turn can activate a positive feedback on DC themselves by boosting their maturation, their infiltration and favoring DC/CD4 ${ }^{+} \mathrm{T}$ cell interactions. itDC can also increase infiltration of T cells by secreting chemokines and exert direct cytotoxic effect, resulting in increased tumor cell death and, more importantly, increased release of tumor antigens. The figure was made using the Servier Medical ART set by Servier.

to directly inoculate DC in the tumor. In fact, as summarized in Table 1, itDC trials have been performed against pancreas (27, $38,44)$, liver $(27,37)$, colorectal $(27)$, prostate (39), esophagus (40), brain $(28)$, skin $(26,42)$, lung $(31,35)$, bile duct $(27,35)$, breast, ovarian, bladder, neuroendocrine (35), renal (43), and hematological tumors $(29,30)$, and soft tissue sarcoma (41). With the exception of melanoma (which is clearly accessible), the inoculation of DC was guided by ultrasound, computed tomography scan, or endoscopic ultrasound. Only in the setting of a brain tumor was an intraventricular catheter used (28).

Even though basal tumor apoptosis/necrosis can be exploited $(27,35,44)$, itDC vaccination strongly benefits from tumor pretreatment with death-inducing agents, because of the increased release of tumor antigens (Figure 1A) $(24,26)$. Among the preconditioning regimens used, the ones causing immunogenic cell death are clearly preferred, because they couple the release of tumor antigens with DC activating signals (45-47). However, as shown by Teitz-Tennenbaum, radiotherapy (RT), inducing calreticulin exposure and other activating signals (48, 49), stimulates DC processing ability, homing to lymph node, and their ability to stimulate $\mathrm{T}$ cells even when RT was not inducing tumor cell death (50). This point indicates that itDC can strongly benefit, not only from tumor pre-conditioning with immunogenic cell death treatments, but also with regimens that simply increase immunogenicity of tumors, thus enlarging the range of possible agents that can be used.

Among the several pre-conditioning regimens, RT represents the broadest applicable one considering also the ease of adding itDC into already well-established RT regimens $(24,37,41)$. However, clinical trials have also been performed using local hyperthermia (26), systemic chemotherapy (40), and tumortargeting monoclonal antibodies $(29,30)$ (Table 1). While an ideal pre-condition approach should be tailored to tumor type, the use of tumor-targeting monoclonal antibodies raises some fascinating advantages and synergies. First, considering that DC are endowed with antibody-dependent cell-mediated cytotoxicity (51), the two treatments could directly synergize. In fact, we have shown that direct cytotoxic activity of DC against the lymphoma cell line Karpas-422 was increased after rituximab pre-treatment (30). Second, it has been shown that, for a successful monoclonal therapy, an NK-DC crosstalk needs to be mounted, where NK cell activation leads to increased cross-presentation and maturation of DC, thus resulting in antitumor $\mathrm{T}$ cell activation (52, 53). Therefore, it DC might boost such crosstalk, leading to increased NK cell activity and stronger adaptive antitumor immune responses. Third, combining monoclonal antibody with itDC can potentially lead to in situ vaccination targeted against clinically relevant, rare cells within the tumor, such as cancer stem cells. In fact, even though monoclonal antibodies recognizing cancer stem cells have not yet shown promising results (54), the possibility to directly target CSC with monoclonal antibodies, in combination with it DC to activate $\mathrm{T}$ cell immunity against CSC, may hold great promises and deserves future testing.

\section{itDC, a 360-Degree Immunotherapy}

Even though it DC based therapy is principally aimed at direct in situ vaccination, several complementary immunotherapy effects can also result (Figure 1B). As clearly shown by pre-clinical studies on itDC, NK cells can be directly targeted and activated by itDC $(55,56)$. In fact, depletion of NK cells led to impaired efficacy of itDC. This is not surprising in light of the tight crosstalk existing between DC and NK cells $(57,58)$. On one side, DC can potently activate NK cell cytotoxicity against tumor cells through secreted cytokines and cell-to-cell contact $(59,60)$. This, in turn, stimulates NK cells to secrete CCL5, XCL1, and Flt3L in the tumor $(61,62)$, thus promoting natural DC infiltration and additional cross-priming of tumor-associated antigen (63). On the other side, NK cells can strongly enhance DC maturation and IL-12 production, stimulate CD4 T cell response and, through IFN- $\gamma$, help DC-driven Th1 polarization $(64,65)$. In line with this crosstalk, it has been observed that high levels of NK cells after DC vaccination correlated with clinical response in acute myeloid leukemia (66) and advanced hepatoma patients (37).

Another complementary effect of itDC that should be taken into account is the ability of DC (especially upon maturation) to secrete several chemokines that can favor the infiltration of $\mathrm{T}$ cells and endogenous DC in the tumor microenvironment. This possibility has been recently tested in renal cell carcinoma by injecting allogeneic DC, therefore, excluding any direct vaccination effect but rather potentiating inflammatory-related signals due to cell allogeneity (43). Notably, the authors observed a high level of $\mathrm{T}$ cell infiltration and induction of tumor specific $\mathrm{T}$ cell responses in three out of 11 evaluable patients. Even more interestingly, despite clinical responses not being registered, an unexpected response consisting in high infiltration of $\mathrm{T}$ cells was observed in patients subsequently treated with tyrosine kinase inhibitors, thus suggesting a synergistic effect of the alloitDC with tyrosine kinase inhibitors, possibly mediated by their effect against Treg and MDSC $(43,67)$. This approach has been additionally tested in advanced hepatocellular carcinoma patients where induction of tumor-specific immune activation in a substantial number of patients was observed (68). Alternative to the use of allogeneic cells, another approach to boost itDC ability to inflame the tumor and/or stimulate immune cells has been 
tested by genetically modifying DC for constitutive expression of activating factors. DC transduced for the expression of IL-7, IL12 , IL-15, IFN- $\alpha$, and CCL21 have all been tested in pre-clinical models of it DC showing encouraging results (20, 21, 25, 55, 69, $70)$, even though clinical experience with IL-12 transduced DC showed limited success $(27,36)$.

Lastly, despite being usually neglected, DC are also characterized by direct tumoricidal activity, which, in the context of itDC, might result in additional tumor cell death and more importantly in increased release of tumor antigens and damage associated molecular patterns, thus potentiating immune reactivation. In fact, ex vivo generated DC, circulating conventional DC and plasmacytoid DC exert direct cytotoxicity against tumor cells (51). This ability has been demonstrated against a large variety of cancer cell lines and can be mediated by both cell-to-cell signals and secreted factors. While TRAIL is the major signal by which DC exert their tumoricidal activity (71), TNF $\alpha$, FAS-L, caspase-8, IFN- $\gamma$, and Granzyme B can also play a role (51).

\section{The Ideal DC Phenotype for itDC Immunotherapy: Lessons Learned}

Conversely to the classical antigen-loaded DC vaccination approach, for which many different protocols for DC differentiation and maturation have been developed and compared $(4,72,73)$, minimal discussion has been raised regarding the phenotype of DC to be used for intratumoral inoculation. Initial studies focused on the use of immature DC to take advantage of enhanced phagocytic and antigen processing ability of these cells over the mature counterparts $(21,25,74)$. However, in absence of strong DC activating stimuli (i.e., when tumor pre-conditioning is not performed or not inducing strong immunogenic cell death), immature DC can have a detrimental effect exerting more immunosuppressive rather than immunostimulatory activity (75-78). Therefore, a semi-mature phenotype may be preferable to couple phagocytic activity with the predefined immunostimulatory mature phenotype (35). However, additional immunotherapy effects of itDC (see above) should also be taken into account.

While other protocols to generate semi-mature DC have been developed $(79,80)$, we opted for DC differentiated in the presence of IFN- $\alpha$ instead of IL-4 $(30,42)$. These cells (named as IFN-DC) have been discovered by our group almost 20 years ago and are characterized by a partially mature phenotype and are endowed with a high migratory behavior and immunostimulatory ability (81-83). They have been shown to be more efficient than conventional IL-4-DC in internalizing tumor antigens and in the cross-priming of $\mathrm{CD}^{+} \mathrm{T}$ cells, thus promoting anti-tumor immune responses $(84,85)$. Moreover, it has been shown that IFN-DC can promote efficient NK cell activation, increase expression of cytotoxicity receptors, and stimulate extensive IFN- $\gamma$ production by NK cells (86). Interestingly, in two different clinical trials, we observed induction of long-term $\mathrm{T}$ cell immune response against tumor associated antigens upon itDC immunotherapy using IFN-DC $(30,42)$.

\section{The Coming of Age of itDC: Clinical and Immunological Responses in Recent Trials}

While initial attempts of itDC showed limited success, recent trials have convincingly shown not only safety and feasibility of itDC immunotherapy, but also clear-cut clinical and immunological responses in a high percentage of patients (Table 1). In two studies in follicular lymphoma patients, it DC in combination with low-dose rituximab alone (30) or in combination with low-dose rituximab, plus local radiotherapy, and GM-CSF (29), showed induction of 50 and $36 \%$, respectively, of objective clinical responses in treated and untreated lesions. Notably, in both studies, induction of both CD8 and CD4 antitumor specific responses were collected and the magnitude of immune activation appeared to correlate with clinical response. Despite several differences between the two trials (type of DC used, pre-conditioning regimen, treatment schedule), these two studies clearly indicate that follicular lymphoma is particularly suited for itDC and that this immunotherapy approach is worth being tested in phase II-III clinical trials.

In another interesting clinical study, Lee et al. used CCL21 transduced DC in NSCLC (31). Despite minimal clinical effects being recorded, induction of $\mathrm{T}$ cell responses against tumor associated antigens were observed in 6/16 patients and, in four patients, induction of humoral response was reported. However, more noteworthy is the observation that, with only two DC inoculations, an increase in CD8 T cell infiltration was observed in $56 \%$ of patients and that this was correlated with increased expression of checkpoint inhibitors (31). Similar results were collected by another study using activated DC in several tumor types, showing that increased PDL1 expression in the majority of patients usually paired by $\mathrm{T}$ cell infiltration (35). Thus, altogether both studies suggest that it DC itself increased PD-L1 expression as a result of antigen recognition and $\mathrm{CD} 8 \mathrm{~T}$ cell infiltration at the tumor site, clearly pointing to synergies that can result by combining itDC and checkpoint blockade.

\section{itDC for Checkpoint Blockade Immunotherapy: Arming T Cells While Preparing the Battlefield}

Checkpoint blockade is revolutionizing cancer therapy with impressive long-term responses in a large variety of tumors. However, the majority of patients still do not benefit from this therapy because of either primary or secondary resistance (87). Several factors have been identified playing a role behind response to checkpoint blockade: tumor mutation burden (88), PDL1 expression $(89,90)$, T cell inflamed microenvironment (91), T cell repertoire richness and clonality (92), HLA-I diversity (93), intestinal microbiota $(94,95)$, and specific mutations have all been identified as potential markers with prognostic or predictive value in checkpoint blockade therapy (87). Additionally, cross-priming and CXCL9/10 secretion mediated 
A

B
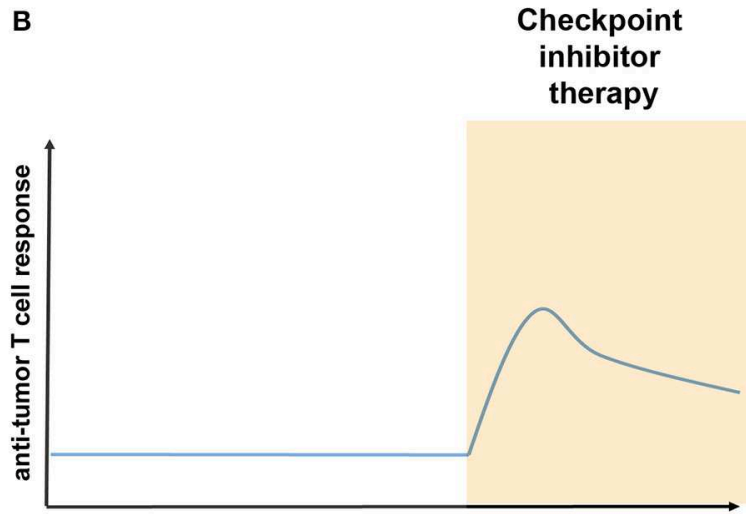

C

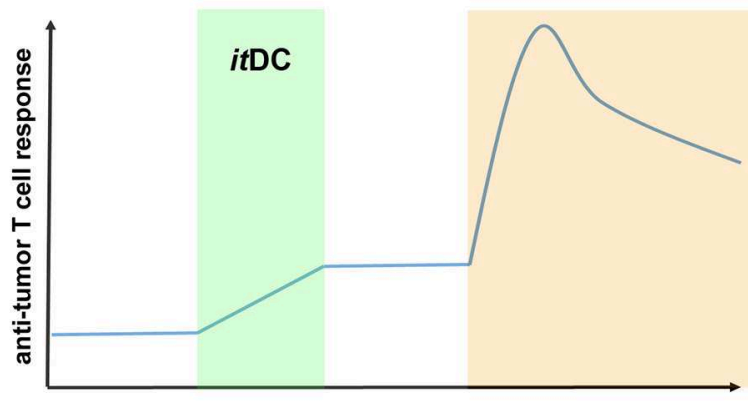

D

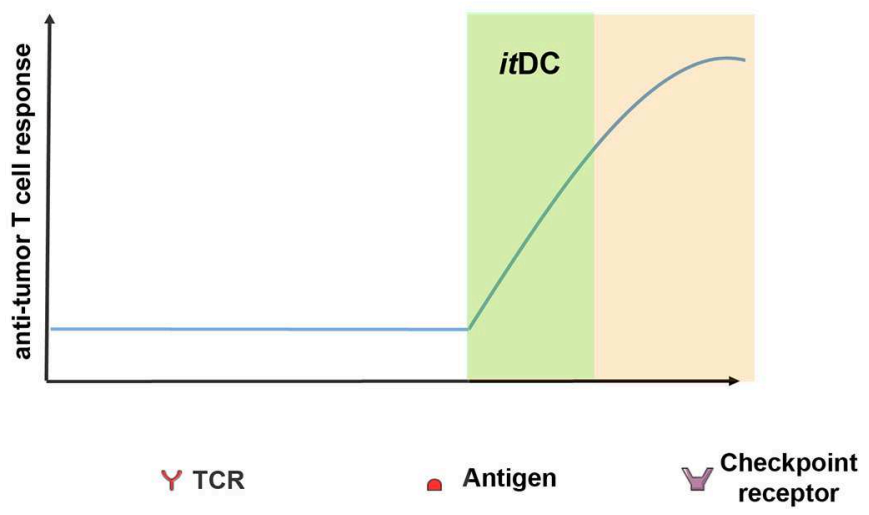

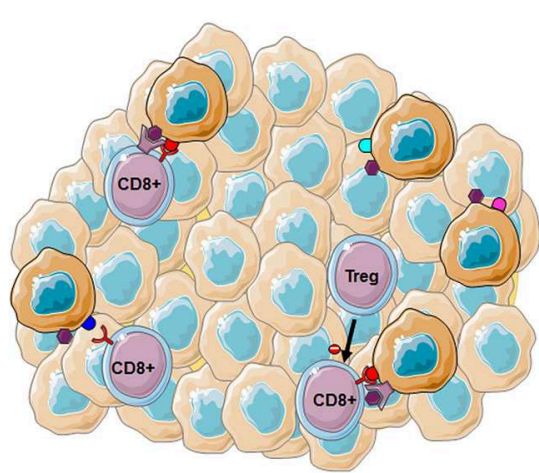
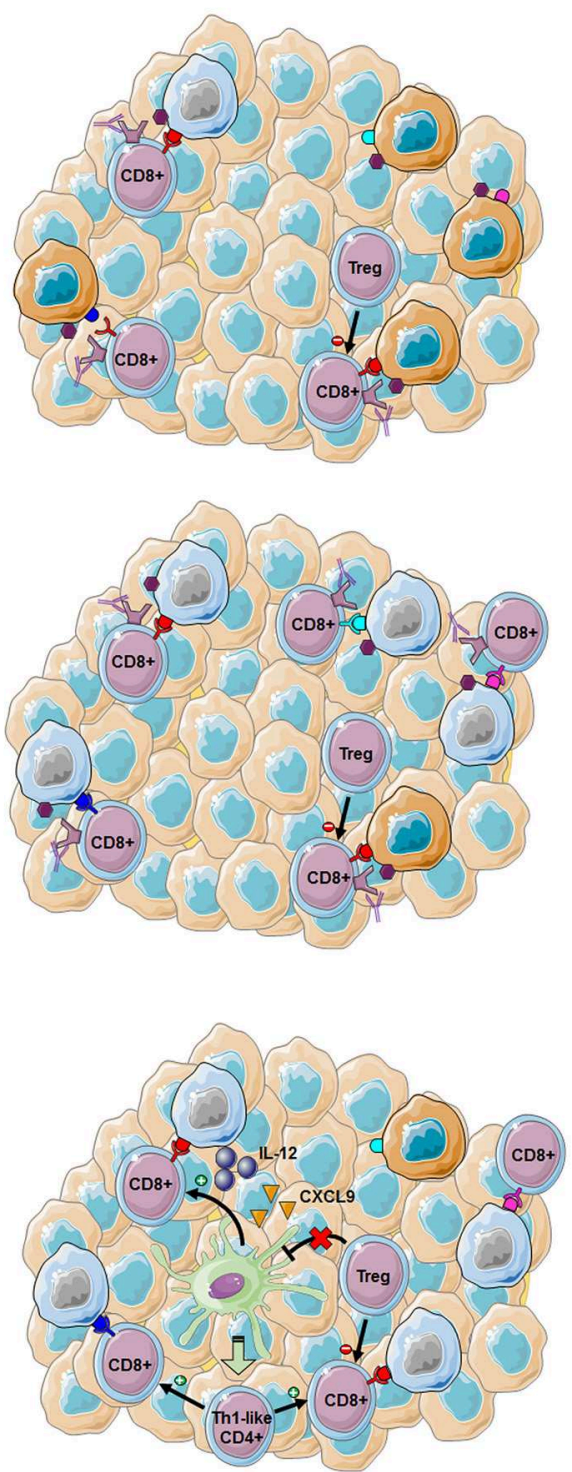

Checkpoint YCheckpoint

FIGURE 2 | Expected advantages of integrating the "itDC" approach in the context of the checkpoint blockade therapy. (A) In poorly immunogenic tumors, T cell response is usually low due to multiple checkpoint inhibitors expressed within the tumor microenvironment and immunosuppressive cells. (B) Checkpoint blockade 
FIGURE 2 | therapy may result in increased antitumor T cell response of pre-existing antitumor clones. However, reduced richness and clonality, together with the presence of Treg cell limits checkpoint blockade efficacy, thus resulting in short-lived responses in the majority of patients. (C) itDC immunotherapy administered prior to checkpoint blockade therapy may lead to increased T cell clonality and richness. In this setting, subsequent checkpoint inhibitor administration is expected to lead to broader antitumor T cell activation. (D) itDC immunotherapy taking place during checkpoint blockade therapy may boost intratumor T cell activation by secreting IL-12, CXCL9. Additionally, it could overcome inhibitory signals from Treg cells, thus unleashing activation and infiltration of Th1-like CD4 ${ }^{+} \mathrm{T}$ cells that can further potentiate antitumor T cell response (97-99). The figure was made using the Servier Medical ART set by Servier.

by intratumoral $\mathrm{CD}_{103}{ }^{+}$BATF3-dependent dendritic cells has also been correlated with response to checkpoint blockade $(17,96)$. Notably, it DC studies have already been shown to lead to increased tumor PDL1 expression and increased $\mathrm{T}$ cell responses in several tumor types $(31,35)$. In our recent study, combining NGS technology with in silico prediction, we analyzed $\mathrm{T}$ cell responses against patient specific mutations in follicular lymphoma patients before and after itDC and observed an increase in pre-existing $\mathrm{T}$ cell responses in some patients. This, thus, indicates increased $\mathrm{T}$ cell clonality and induction (within the limit of assay detection) of de novo $\mathrm{T}$ cell response, suggesting increased $\mathrm{T}$ cell richness of antigenic repertoire (30). Altogether, the evidences gained in clinical studies and animal models with itDC imply that checkpoint blockade therapy could be enhanced by prior itDC immunotherapy (Figure 2).

Interestingly, the role of intratumoral DC subsets in response to checkpoint blockade therapy has recently emerged, depicting two independent axis: an NK/cDC1/IL-12-CXCL9 axis needed for effective CD8 T cell response and a Treg/cDC2 axis for effective CD4 $\mathrm{T}$ cell response. In one study mainly focused on melanoma, Barry et al. have described the role of intratumoral $\mathrm{NK}$ cells in increasing $\mathrm{CDC1}$ abundance within a tumor microenvironment by secreting FLT3LG, showing that the abundance of both populations positively correlates with the response to checkpoint blockade therapy (62). Further, recent literature has unraveled how intratumoral cDC1 "license" CD8 response during checkpoint blockade by secreting IL-12 and CXCL9, potentiating $\mathrm{T}$ cell activation $(97,98)$. On the other side, Binnewies et al. have discovered that levels of $\mathrm{cDC} 2$ populations relative to Treg abundance within tumor microenvironment are responsible of infiltration by $\mathrm{CD} 4 \mathrm{~T}$ cells and correlate with the response to checkpoint blockade therapy (99). Whether it DC during checkpoint blockade therapy could potentiate $\mathrm{T}$ cell activity by secreting IL-12, CXCL9 or by overcoming inhibitory activity of Treg has not yet been analyzed. However, it is reasonable to expect that activated itDC will sum up with intratumoral $\mathrm{DC}$ in sustaining $\mathrm{T}$ cell responses during checkpoint blockade therapy (Figure 2).

\section{REFERENCES}

1. Sallusto F, Lanzavecchia A. Efficient presentation of soluble antigen by cultured human dendritic cells is maintained by granulocyte/macrophage colony-stimulating factor plus interleukin 4 and downregulated by tumor necrosis factor alpha. J Exp Med. (1994) 179:1109-18. doi: $10.1084 /$ jem.179.4.1109

\section{CONCLUSIONS AND PERSPECTIVES}

The intratumoral delivery of DC has been tested in several different clinical settings, where it has been proved to not only be feasible and safe, but also to be capable of enhancing and/or inducing a tumor-specific immune response.

The possibility to exploit, by an endogenous vaccination strategy, the broad tumor antigen repertoire promptly released by immunogenic tumor pre-conditioning, makes it $\mathrm{DC}$ a versatile cell therapy, potentially overcoming some of the limitations of therapies based on ex-vivo antigen loaded DC, such as the lack of dominant tumor antigens, the availability of tumor samples, and the possible emergence of neo-antigens.

Although the limited number of patients enrolled in phase I studies demands a prudent evaluation of the observed clinical results, data collected so far look promising, and encourages the application of itDC to hitherto unexplored clinical settings. More research efforts should yet be devoted to the identification of the optimal DC types to be used in $i t \mathrm{DC}$ strategies, as well as of the most effective strategies for tumor microenvironment pre-conditioning tailored for specific clinical settings. Of note, the accumulating knowledge on their mechanism of action, by showing that it DC can affect tumor microenvironment at different levels (including cytokine release and NK cells stimulation), also provides the rationale for their use in combination with immunotherapy approaches currently used in oncology, such as immune checkpoint inhibitors. Based on the evidence available, summarized in this review, we envisage that it DC, administered prior or in concomitance with checkpoint inhibitors, by triggering a broader and more effective antitumor immune response, can not only prolong their efficacy, but also provide clinical benefit to patients showing limited responsiveness to checkpoint inhibitors per se.

\section{AUTHOR CONTRIBUTIONS}

LC, EA, and FB wrote the manuscript. LC and EA prepared the figures. All authors contributed to manuscript revision, read, and approved the submitted version.

2. Garg AD, Vara Perez M, Schaaf M, Agostinis P, Zitvogel L, Kroemer G, et al. Trial watch: dendritic cell-based anticancer immunotherapy. Oncoimmunology. (2017) 6:e1328341. doi: 10.1080/2162402X.2017.13 28341

3. Butterfield LH. Dendritic cells in cancer immunotherapy clinical trials: are we making progress? Front Immunol. (2013) 4:454. doi: 10.3389/fimmu.2013.00454 
4. Castiello L, Sabatino M, Jin P, Clayberger C, Marincola FM, Krensky AM, et al. Monocyte-derived DC maturation strategies and related pathways: a transcriptional view. Cancer Immunol Immunother. (2011) 60:457-66. doi: 10.1007/s00262-010-0954-6

5. Villani A-C, Satija R, Reynolds G, Sarkizova S, Shekhar K, Fletcher J, et al. Single-cell RNA-seq reveals new types of human blood dendritic cells, monocytes, and progenitors. Science. (2017) 356:eaah4573. doi: 10.1126/science.aah4573

6. Anguille S, Smits EL, Lion E, van Tendeloo VF, Berneman ZN. Clinical use of dendritic cells for cancer therapy. Lancet Oncol. (2014) 15:e257-67. doi: 10.1016/S1470-2045(13)70585-0

7. Liau LM, Ashkan K, Tran DD, Campian JL, Trusheim JE, Cobbs CS, et al. First results on survival from a large Phase 3 clinical trial of an autologous dendritic cell vaccine in newly diagnosed glioblastoma. J Transl Med. (2018) 16:142. doi: 10.1186/s12967-018-1507-6

8. Tanyi JL, Bobisse S, Ophir E, Tuyaerts S, Roberti A, Genolet R, et al. Personalized cancer vaccine effectively mobilizes antitumor $\mathrm{T}$ cell immunity in ovarian cancer. Sci Transl Med. (2018) 10:eaao5931. doi: 10.1126/scitranslmed.aao5931

9. Carreno BM, Magrini V, Becker-Hapak M, Kaabinejadian S, Hundal J, Petti AA, et al. A dendritic cell vaccine increases the breadth and diversity of melanoma neoantigen-specific T cells. Science. (2015) 348:803-8. doi: $10.1126 /$ science.aaa3828

10. Garg AD, Coulie PG, Van den Eynde BJ, Agostinis P. Integrating nextgeneration dendritic cell vaccines into the current cancer immunotherapy landscape. Trends Immunol. (2017) 38:577-93. doi: 10.1016/j.it.2017.05.006

11. Hammerich L, Binder A, Brody JD. In situ vaccination: cancer immunotherapy both personalized and off-the-shelf. Mol Oncol. (2015) 9:1966-81. doi: 10.1016/j.molonc.2015.10.016

12. Chiang CL-L, Kandalaft LE. In vivo cancer vaccination: which dendritic cells to target and how? Cancer Treat Rev. (2018) 71:88-101. doi: 10.1016/j.ctrv.2018.10.012

13. Aznar MA, Tinari N, Rullán AJ, Sánchez-Paulete AR, Rodriguez-Ruiz ME, Melero I. Intratumoral delivery of immunotherapy-act locally, think globally. J Immunol. (2017) 198:31-9. doi: 10.4049/jimmunol.1601145

14. Brody JD, Goldstein MJ, Czerwinski DK, Levy R. Immunotransplantation preferentially expands T-effector cells over T-regulatory cells and cures large lymphoma tumors. Blood. (2009) 113:85-94. doi: 10.1182/blood-2008-05-155457

15. Kim YH, Gratzinger D, Harrison C, Brody JD, Czerwinski DK, Ai WZ, et al. In situ vaccination against mycosis fungoides by intratumoral injection of a TLR9 agonist combined with radiation: a phase 1/2 study. Blood. (2012) 119:355-63. doi: 10.1182/blood-2011-05-355222

16. Frank MJ, Reagan PM, Bartlett NL, Gordon LI, Friedberg JW, Czerwinski DK, et al. In situ vaccination with a TLR9 agonist and local low-dose radiation induces systemic responses in untreated indolent lymphoma. Cancer Discov. (2018) 8:1258-69. doi: 10.1158/2159-8290.CD-18-0743

17. Salmon H, Idoyaga J, Rahman A, Leboeuf M, Remark R, Jordan S, et al. Expansion and activation of CD103 + dendritic cell progenitors at the tumor site enhances tumor responses to therapeutic PD-L1 and BRAF inhibition. Immunity. (2016) 44:924-38. doi: 10.1016/j.immuni.2016.03.012

18. Sánchez-Paulete AR, Teijeira Á, Quetglas JI, Rodríguez-Ruiz ME, SánchezArráez Á, Labiano S, et al. Intratumoral immunotherapy with XCL1 and sFlt3L encoded in recombinant semliki forest virus-derived vectors fosters dendritic cell-mediated T-cell cross-priming. Cancer Res. (2018) 78:6643-54. doi: 10.1158/0008-5472.CAN-18-0933

19. Hammerich L, Marron TU, Upadhyay R, Svensson-Arvelund J, Dhainaut $\mathrm{M}$, Hussein S, et al. Systemic clinical tumor regressions and potentiation of PD1 blockade with in situ vaccination. Nat Med. (2019) 25:814-24. doi: 10.1038/s41591-019-0410-x

20. Sharma S, Miller P, Stolina M, Zhu L, Huang M, Paul R, et al. Multicomponent gene therapy vaccines for lung cancer: effective eradication of established murine tumors in vivo with interleukin-7/herpes simplex thymidine kinasetransduced autologous tumor and ex vivo activated dendritic cells. Gene Ther. (1997) 4:1361-70. doi: 10.1038/sj.gt.3300531

21. Melero I, Duarte M, Ruiz J, Sangro B, Galofré JC, Mazzolini G, et al. Intratumoral injection of bone-marrow derived dendritic cells engineered to produce interleukin-12 induces complete regression of established murine transplantable colon adenocarcinomas. Gene Ther. (1999) 6:1779-84 doi: $10.1038 /$ sj.gt.3301010

22. Triozzi PL, Khurram R, Aldrich WA, Walker MJ, Kim JA, Jaynes S. Intratumoral injection of dendritic cells derived in vitro in patients with metastatic cancer. Cancer. (2000) 89:2646-54. doi: 10.1002/1097-0142(20001215)89:12<2646::AID-CNCR18>3.0.CO;2-A

23. Yu B, Kusmartsev S, Cheng F, Paolini M, Nefedova Y, Sotomayor E, et al. Effective combination of chemotherapy and dendritic cell administration for the treatment of advanced-stage experimental breast cancer. Clin Cancer Res. (2003) 9:285-94.

24. Teitz-Tennenbaum S, Li Q, Rynkiewicz S, Ito F, Davis MA, McGinn CJ, et al. Radiotherapy potentiates the therapeutic efficacy of intratumoral dendritic cell administration. Cancer Res. (2003) 63:8466-75.

25. Miller PW, Sharma S, Stolina M, Butterfield LH, Luo J, Lin Y, et al. Intratumoral administration of adenoviral interleukin 7 genemodified dendritic cells augments specific antitumor immunity and achieves tumor eradication. Hum Gene Ther. (2000) 11:53-65. doi: 10.1089/10430340050016157

26. Guo J, Zhu J, Sheng X, Wang X, Qu L, Han Y, et al. Intratumoral injection of dendritic cells in combination with local hyperthermia induces systemic antitumor effect in patients with advanced melanoma. Int J Cancer. (2007) 120:2418-25. doi: 10.1002/ijc.22551

27. Mazzolini G, Alfaro C, Sangro B, Feijoó E, Ruiz J, Benito A, et al. Intratumoral injection of dendritic cells engineered to secrete interleukin12 by recombinant adenovirus in patients with metastatic gastrointestinal carcinomas. J Clin Oncol. (2005) 23:999-1010. doi: 10.1200/JCO.2005.00.463

28. Yamanaka R, Homma J, Yajima N, Tsuchiya N, Sano M, Kobayashi T, et al. Clinical evaluation of dendritic cell vaccination for patients with recurrent glioma: results of a clinical phase I/II trial. Clin Cancer Res. (2005) 11:4160-7. doi: 10.1158/1078-0432.CCR-05-0120

29. Kolstad A, Kumari S, Walczak M, Madsbu U, Hagtvedt T, Bogsrud TV, et al. Sequential intranodal immunotherapy induces anti-tumor immunity and correlated regression of disseminated follicular lymphoma. Blood. (2015) 125:82-9. doi: 10.1182/blood-2014-07-592162

30. Cox MC, Castiello L, Mattei M, Santodonato L, D’Agostino G, Muraro E, et al. Clinical and antitumor immune responses in relapsed/refractory follicular lymphoma patients after intranodal injections of IFN $\alpha$ dendritic cells and rituximab. Clin Cancer Res. (2019) 25:5231-41. doi: 10.1158/1078-0432.CCR-19-0709

31. Lee JM, Lee M-H, Garon E, Goldman JW, Salehi-Rad R, Baratelli FE, et al. Phase I trial of intratumoral injection of CCL21 gene-modified dendritic cells in lung cancer elicits tumor-specific immune responses and CD8 + T-cell infiltration. Clin Cancer Res. (2017) 23:4556-68. doi: 10.1158/1078-0432.CCR-16-2821

32. Steinman RM. Dendritic cells: understanding immunogenicity. Eur $J$ Immunol. (2007) 37:S53-60. doi: 10.1002/eji.200737400

33. Binnewies M, Roberts EW, Kersten K, Chan V, Fearon DF, Merad M, et al. Understanding the tumor immune microenvironment (TIME) for effective therapy. Nat Med. (2018) 24:541-50. doi: 10.1038/s41591-018-0014-x

34. Böttcher JP, Reis E, Sousa C. The role of type 1 conventional dendritic cells in cancer immunity. Trends Cancer. (2018) 4:784-92. doi: 10.1016/j.trecan.2018.09.001

35. Subbiah V, Murthy R, Hong DS, Prins RM, Hosing C, Hendricks K, et al. Cytokines produced by dendritic cells administered intratumorally correlate with clinical outcome in patients with diverse cancers. Clin Cancer Res. (2018) 24:3845-56. doi: 10.1158/1078-0432.CCR-17-2707

36. Feijoó E, Alfaro C, Mazzolini G, Serra P, Peñuelas I, Arina A, et al. Dendritic cells delivered inside human carcinomas are sequestered by interleukin-8. Int $J$ Cancer. (2005) 116:275-81. doi: 10.1002/ijc.2 1046

37. Chi K-H, Liu S-J, Li C-P, Kuo H-P, Wang Y-S, Chao Y, et al. Combination of conformal radiotherapy and intratumoral injection of adoptive dendritic cell immunotherapy in refractory hepatoma. J Immunother. (2005) 28:129-35. doi: 10.1097/01.cji.0000154248.74383.5e

38. Hirooka Y, Itoh A, Kawashima H, Hara K, Nonogaki K, Kasugai T, et al. A combination therapy of gemcitabine with immunotherapy for patients with inoperable locally advanced pancreatic cancer. Pancreas. (2009) 38:e69-74. doi: 10.2958 /suizo. 24.632 
39. Finkelstein SE, Rodriguez F, Dunn M, Farmello M-J, Smilee R, Janssen $\mathrm{W}$, et al. Serial assessment of lymphocytes and apoptosis in the prostate during coordinated intraprostatic dendritic cell injection and radiotherapy. Immunotherapy. (2012) 4:373-82. doi: 10.2217/imt.12.24

40. Fujiwara S, Wada H, Miyata H, Kawada J, Kawabata R, Nishikawa H, et al. Clinical trial of the intratumoral administration of labeled DC combined with systemic chemotherapy for esophageal cancer. J Immunother. (2012) 35:513-21. doi: 10.1097/CJI.0b013e3182619cb4

41. Finkelstein SE, Iclozan C, Bui MM, Cotter MJ, Ramakrishnan R, Ahmed J, et al. Combination of external beam radiotherapy (EBRT) with intratumoral injection of dendritic cells as neo-adjuvant treatment of high-risk soft tissue sarcoma patients. Int J Radiat Oncol Biol Phys. (2012) 82:924-32. doi: 10.1016/j.ijrobp.2010.12.068

42. Rozera C, Cappellini GA, D’Agostino G, Santodonato L, Castiello L, Urbani F, et al. Intratumoral injection of IFN-alpha dendritic cells after dacarbazine activates anti-tumor immunity: results from a phase I trial in advanced melanoma. J Transl Med. (2015) 13:139. doi: 10.1186/s12967-0150473-5

43. Laurell A, Lönnemark M, Brekkan E, Magnusson A, Tolf A, Wallgren AC, et al. Intratumorally injected pro-inflammatory allogeneic dendritic cells as immune enhancers: a first-in-human study in unfavourable risk patients with metastatic renal cell carcinoma. J Immunother Cancer. (2017) 5:52. doi: 10.1186/s40425-017-0255-0

44. Endo H, Saito T, Kenjo A, Hoshino M, Terashima M, Sato T, et al. Phase I trial of preoperative intratumoral injection of immature dendritic cells and OK-432 for resectable pancreatic cancer patients. $J$ Hepatobiliary Pancreat Sci. (2012) 19:465-75. doi: 10.1007/s00534-0110457-7

45. Galluzzi L, Buqué A, Kepp O, Zitvogel L, Kroemer G. Immunogenic cell death in cancer and infectious disease. Nat Rev Immunol. (2017) 17:97-111. doi: $10.1038 /$ nri.2016.107

46. Suek N, Campesato LF, Merghoub T, Khalil DN. Targeted APC activation in cancer immunotherapy to enhance the abscopal effect. Front Immunol. (2019) 10:604. doi: 10.3389/fimmu.2019. 00604

47. Obeid M, Tesniere A, Ghiringhelli F, Fimia GM, Apetoh L, Perfettini J-L, et al. Calreticulin exposure dictates the immunogenicity of cancer cell death. Nat Med. (2007) 13:54-61. doi: 10.1038/nm1523

48. Obeid M, Panaretakis T, Joza N, Tufi R, Tesniere A, van Endert P, et al. Calreticulin exposure is required for the immunogenicity of $\gamma$-irradiation and UVC light-induced apoptosis. Cell Death Differ. (2007) 14:1848-50. doi: 10.1038/sj.cdd.4402201

49. Galluzzi L, Kepp O, Kroemer G. Immunogenic cell death in radiation therapy. Oncoimmunology. (2013) 2:e26536. doi: 10.4161/onci.26536

50. Teitz-Tennenbaum S, Li Q, Okuyama R, Davis MA, Sun R, Whitfield J, et al. Mechanisms involved in radiation enhancement of intratumoral dendritic cell therapy. JImmunother. (2008) 31:345-58. doi: 10.1097/CJI.0b013e318163628c

51. Tel J, Anguille S, Waterborg CEJ, Smits EL, Figdor CG, de Vries IJM. Tumoricidal activity of human dendritic cells. Trends Immunol. (2014) 35:3846. doi: 10.1016/j.it.2013.10.007

52. Srivastava RM, Lee SC, Andrade Filho PA, Lord CA, Jie H-B, Davidson $\mathrm{HC}$, et al. Cetuximab-Activated natural killer and dendritic cells collaborate to trigger tumor antigen-specific T-cell immunity in head and neck cancer patients. Clin Cancer Res. (2013) 19:1858-72. doi: 10.1158/1078-0432.CCR-12-2426

53. Trivedi S, Srivastava RM, Concha-Benavente F, Ferrone S, Garcia-Bates TM, Li J, et al. Anti-EGFR targeted monoclonal antibody isotype influences antitumor cellular immunity in head and neck cancer patients. Clin Cancer Res. (2016) 22:5229-37. doi: 10.1158/1078-0432.CCR-15-2971

54. Sneha S, Nagare RP, Priya SK, Sidhanth C, Pors K, Ganesan TS. Therapeutic antibodies against cancer stem cells: a promising approach. Cancer Immunol Immunother. (2017) 66:1383-98. doi: 10.1007/s00262-0172049-0

55. Vera M, Razquin N, Prieto J, Melero I, Fortes P, González-Aseguinolaza G. Intratumoral injection of dendritic cells transduced by an SV40based vector expressing interleukin-15 induces curative immunity mediated by $\mathrm{CD}^{+} \mathrm{T}$ lymphocytes and NK cells. Mol Ther. (2005) 12:950-9. doi: 10.1016/j.ymthe.2005.03.030
56. Hu J, Yuan X, Belladonna ML, Ong JM, Wachsmann-Hogiu S, Farkas DL, et al. Induction of potent antitumor immunity by intratumoral injection of interleukin 23-transduced dendritic cells. Cancer Res. (2006) 66:8887-96. doi: 10.1158/0008-5472.CAN-05-3448

57. Kalinski P, Mailliard RB, Giermasz A, Zeh HJ, Basse P, Bartlett DL, et al. Natural killer-dendritic cell cross-talk in cancer immunotherapy. Expert Opin Biol Ther. (2005) 5:1303-15. doi: 10.1517/14712598.5.10.1303

58. Van Elssen CHMJ, Oth T, Germeraad WTV, Bos GMJ, Vanderlocht J. Natural killer cells: the secret weapon in dendritic cell vaccination strategies. Clin Cancer Res. (2014) 20:1095-103. doi: 10.1158/1078-0432.CCR-13-2302

59. Ferlazzo G, Tsang ML, Moretta L, Melioli G, Steinman RM, Münz C. Human dendritic cells activate resting natural killer (NK) cells and are recognized via the NKp30 receptor by activated NK cells. J Exp Med. (2002) 195:343-51. doi: 10.1084/jem.20011149

60. Fernandez NC, Lozier A, Flament C, Ricciardi-Castagnoli P, Bellet D, Suter $\mathrm{M}$, et al. Dendritic cells directly trigger NK cell functions: cross-talk relevant in innate anti-tumor immune responses in vivo. Nat Med. (1999) 5:405-11. doi: $10.1038 / 7403$

61. Böttcher JP, Bonavita E, Chakravarty P, Blees H, Cabeza-Cabrerizo M, Sammicheli S, et al. NK cells stimulate recruitment of $\mathrm{CDC1}$ into the tumor microenvironment promoting cancer immune control. Cell. (2018) 172:102237.e14. doi: 10.1016/j.cell.2018.01.004

62. Barry KC, Hsu J, Broz ML, Cueto FJ, Binnewies M, Combes AJ, et al. A natural killer-dendritic cell axis defines checkpoint therapyresponsive tumor microenvironments. Nat Med. (2018) 24:1178-91. doi: 10.1038/s41591-018-0085-8

63. Liu C, Lou Y, Lizée G, Qin H, Liu S, Rabinovich B, et al. Plasmacytoid dendritic cells induce NK cell-dependent, tumor antigen-specific T cell crosspriming and tumor regression in mice. J Clin Invest. (2008) 118:1165-75. doi: $10.1172 /$ JCI33583

64. Gerosa F, Baldani-Guerra B, Nisii C, Marchesini V, Carra G, Trinchieri G. Reciprocal activating interaction between natural killer cells and dendritic cells. J Exp Med. (2002) 195:327-33. doi: 10.1084/jem.20010938

65. Martín-Fontecha A, Thomsen LL, Brett S, Gerard C, Lipp M, Lanzavecchia A, et al. Induced recruitment of NK cells to lymph nodes provides IFN- $\gamma$ for TH1 priming. Nat Immunol. (2004) 5:1260-5. doi: 10.1038/ni1138

66. Van Tendeloo VF, Van de Velde A, Van Driessche A, Cools N, Anguille S, Ladell $\mathrm{K}$, et al. Induction of complete and molecular remissions in acute myeloid leukemia by Wilms' tumor 1 antigen-targeted dendritic cell vaccination. Proc Natl Acad Sci USA. (2010) 107:13824-9. doi: 10.1073/pnas.1008051107

67. Aparicio LMA, Fernandez IP, Cassinello J. Tyrosine kinase inhibitors reprogramming immunity in renal cell carcinoma: rethinking cancer immunotherapy. Clin Transl Oncol. (2017) 19:1175-82. doi: 10.1007/s12094-017-1657-7

68. Rizell M, Sternby Eilard M, Andersson M, Andersson B, KarlssonParra A, Suenaert P. Phase 1 trial with the cell-based immune primer ilixadencel, alone, and combined with sorafenib, in advanced hepatocellular carcinoma. Front Oncol. (2019) 9:19. doi: 10.3389/fonc.2019.0 0019

69. Huang C, Ramakrishnan R, Trkulja M, Ren X, Gabrilovich DI. Therapeutic effect of intratumoral administration of DCs with conditional expression of combination of different cytokines. Cancer Immunol Immunother. (2012) 61:573-9. doi: 10.1007/s00262-011-1198-9

70. Yang S-C, Hillinger S, Riedl K, Zhang L, Zhu L, Huang M, et al. Intratumoral administration of dendritic cells overexpressing CCL21 generates systemic antitumor responses and confers tumor immunity. Clin Cancer Res. (2004) 10:2891-901. doi: 10.1158/1078-0432.CCR-03-0380

71. Liu S, Yu Y, Zhang M, Wang W, Cao X. The involvement of TNF-related apoptosis-inducing ligand in the enhanced cytotoxicity of IFN-stimulated human dendritic cells to tumor cells. J Immunol. (2001) 166:5407-15. doi: 10.4049/jimmunol.166.9.5407

72. Kalinski P, Urban J, Narang R, Berk E, Wieckowski E, Muthuswamy R. Dendritic cell-based therapeutic cancer vaccines: what we have and what we need. Future Oncol. (2009) 5:379-90. doi: 10.2217/fon.09.6

73. Möller I, Michel K, Frech N, Burger M, Pfeifer D, Frommolt P, et al. Dendritic cell maturation with poly(I:C)-based versus PGE2-based cytokine combinations results in differential functional characteristics 
relevant to clinical application. J Immunother. (2008) 31:506-19. doi: 10.1097/CJI.0b013e318177d9e5

74. Koski GK, Koldovsky U, Xu S, Mick R, Sharma A, Fitzpatrick E, et al. A novel dendritic cell-based immunization approach for the induction of durable Th1polarized anti-HER-2/neu responses in women with early breast cancer. $J$ Immunother. (2012) 35:54-65. doi: 10.1097/CJI.0b013e318235f512

75. Bonnotte B, Crittenden M, Larmonier N, Gough M, Vile RG. MIP3alpha transfection into a rodent tumor cell line increases intratumoral dendritic cell infiltration but enhances (facilitates) tumor growth and decreases immunogenicity. J Immunol. (2004) 173:4929-35. doi: 10.4049/jimmunol.173.8.4929

76. Furumoto K, Soares L, Engleman EG, Merad M. Induction of potent antitumor immunity by in situ targeting of intratumoral DCs. J Clin Invest. (2004) 113:774-83. doi: 10.1172/JCI200419762

77. Shurin GV, Ouellette CE, Shurin MR. Regulatory dendritic cells in the tumor immunoenvironment. Cancer Immunol Immunother. (2012) 61:22330. doi: 10.1007/s00262-011-1138-8

78. Zong J, Keskinov AA, Shurin G V., Shurin MR. Tumor-derived factors modulating dendritic cell function. Cancer Immunol Immunother. (2016) 65:821-33. doi: 10.1007/s00262-016-1820-y

79. Udagawa M, Kudo-Saito C, Hasegawa G, Yano K, Yamamoto A, Yaguchi $\mathrm{M}$, et al. Enhancement of immunologic tumor regression by intratumoral administration of dendritic cells in combination with cryoablative tumor pretreatment and bacillus calmette-guerin cell wall skeleton stimulation. Clin Cancer Res. (2006) 12:7465-75. doi: 10.1158/1078-0432.CCR-06-1840

80. López-Relaño J, Martín-Adrados B, Real-Arévalo I, Lozano-Bartolomé J, Abós B, Sánchez-Ramón S, et al. Monocyte-derived dendritic cells differentiated in the presence of lenalidomide display a semi-mature phenotype, enhanced phagocytic capacity, and th1 polarization capability. Front Immunol. (2018) 9:1328. doi: 10.3389/fimmu.2018.01328

81. Santini SM, Lapenta C, Logozzi M, Parlato S, Spada M, Di Pucchio T, et al. Type I interferon as a powerful adjuvant for monocyte-derived dendritic cell development and activity in vitro and in Hu-PBL-SCID mice. J Exp Med. (2000) 191:1777-88. doi: 10.1084/jem.191.10.1777

82. Santodonato L, D'Agostino G, Nisini R, Mariotti S, Monque DM, Spada $\mathrm{M}$, et al. Monocyte-derived dendritic cells generated after a short-term culture with IFN-alpha and granulocyte-macrophage colony-stimulating factor stimulate a potent Epstein-Barr virus-specific CD8+ T cell response. J Immunol. (2003) 170:5195-202. doi: 10.4049/jimmunol.170.10.5195

83. Lapenta C, Santini SM, Logozzi M, Spada M, Andreotti M, Di Pucchio T, et al. Potent immune response against HIV-1 and protection from virus challenge in hu-PBL-SCID mice immunized with inactivated virus-pulsed dendritic cells generated in the presence of IFN- $\alpha$. J Exp Med. (2003) 198:361-7. doi: $10.1084 /$ jem. 20021924

84. Spadaro F, Lapenta C, Donati S, Abalsamo L, Barnaba V, Belardelli F, et al. IFN-a enhances cross-presentation in human dendritic cells by modulating antigen survival, endocytic routing, and processing. Blood. (2012) 119:140717. doi: $10.1182 /$ blood-2011-06-363564

85. Santini SM, Lapenta C, Donati S, Spadaro F, Belardelli F, Ferrantini M. Interferon- $\alpha$-conditioned human monocytes combine a Th1-orienting attitude with the induction of autologous Th17 responses: role of IL-23 and IL-12. PLoS ONE. (2011) 6:e17364. doi: 10.1371/journal.pone.0017364

86. Lapenta C, Donati S, Spadaro F, Castaldo P, Belardelli F, Cox MC, et al. NK cell activation in the antitumor response induced by IFN$\alpha$ dendritic cells loaded with apoptotic cells from follicular lymphoma patients. J Immunol. (2016) 197:795-806. doi: 10.4049/jimmunol.160 0262
87. Havel JJ, Chowell D, Chan TA. The evolving landscape of biomarkers for checkpoint inhibitor immunotherapy. Nat Rev Cancer. (2019) 19:133-50. doi: 10.1038/s41568-019-0116-x

88. Yarchoan M, Hopkins A, Jaffee EM. Tumor mutational burden and response rate to PD-1 inhibition. N Engl J Med. (2017) 377:2500-1. doi: 10.1056/NEJMc1713444

89. Topalian SL, Taube JM, Anders RA, Pardoll DM. Mechanism-driven biomarkers to guide immune checkpoint blockade in cancer therapy. Nat Rev Cancer. (2016) 16:275-87. doi: 10.1038/nrc.2016.36

90. Gibney GT, Weiner LM, Atkins MB. Predictive biomarkers for checkpoint inhibitor-based immunotherapy. Lancet Oncol. (2016) 17:e542-51. doi: 10.1016/S1470-2045(16)30406-5

91. Tumeh PC, Harview CL, Yearley JH, Shintaku IP, Taylor EJM, Robert L, et al. PD-1 blockade induces responses by inhibiting adaptive immune resistance. Nature. (2014) 515:568-71. doi: 10.1038/nature13954

92. Riaz N, Havel JJ, Makarov V, Desrichard A, Urba WJ, Sims JS, et al. Tumor and microenvironment evolution during immunotherapy with nivolumab. Cell. (2017) 171:934-49.e16. doi: 10.1016/j.cell.2017.09.028

93. Chowell D, Morris LGT, Grigg CM, Weber JK, Samstein RM, Makarov $\mathrm{V}$, et al. Patient HLA class I genotype influences cancer response to checkpoint blockade immunotherapy. Science. (2018) 359:582-7. doi: $10.1126 /$ science.aao4572

94. Sivan A, Corrales L, Hubert N, Williams JB, Aquino-Michaels K, Earley ZM, et al. Commensal Bifidobacterium promotes antitumor immunity and facilitates anti-PD-L1 efficacy. Science. (2015) 350:1084-9. doi: $10.1126 /$ science.aac4255

95. Vétizou M, Pitt JM, Daillère R, Lepage P, Waldschmitt N, Flament $C$, et al. Anticancer immunotherapy by CTLA- 4 blockade relies on the gut microbiota. Science. (2015) 350:1079-84. doi: 10.1126/science.aad1329

96. Spranger S, Dai D, Horton B, Gajewski TF. Tumor-residing Batf3 dendritic cells are required for effector $\mathrm{T}$ cell trafficking and adoptive $\mathrm{T}$ cell therapy. Cancer Cell. (2017) 31:711-23.e4. doi: 10.1016/j.ccell.2017.04.003

97. Garris CS, Arlauckas SP, Kohler RH, Trefny MP, Garren S, Piot C, et al. Successful anti-PD-1 cancer immunotherapy requires $\mathrm{T}$ cell-dendritic cell crosstalk involving the cytokines IFN- $\gamma$ and IL-12. Immunity. (2018) 49:114861.e7. doi: 10.1016/j.immuni.2018.09.024

98. Chow MT, Ozga AJ, Servis RL, Frederick DT, Lo JA, Fisher DE, et al. Intratumoral activity of the CXCR3 chemokine system is required for the efficacy of anti-PD-1 therapy. Immunity. (2019) 50:1498-512.e5. doi: 10.1016/j.immuni.2019.04.010

99. Binnewies M, Mujal AM, Pollack JL, Combes AJ, Hardison EA, Barry KC, et al. Unleashing type-2 dendritic cells to drive protective antitumor $\mathrm{CD} 4^{+} \mathrm{T}$ cell immunity. Cell. (2019) 177:556-71.e16. doi: 10.1016/j.cell.2019.02.005

Conflict of Interest: The authors declare that the research was conducted in the absence of any commercial or financial relationships that could be construed as a potential conflict of interest.

The handling editor declared a past co-authorship with one of the authors FB.

Copyright (c) 2019 Castiello, Aricò, D’Agostino, Santodonato and Belardelli. This is an open-access article distributed under the terms of the Creative Commons Attribution License (CC BY). The use, distribution or reproduction in other forums is permitted, provided the original author(s) and the copyright owner(s) are credited and that the original publication in this journal is cited, in accordance with accepted academic practice. No use, distribution or reproduction is permitted which does not comply with these terms. 